\title{
Emotional/Psychiatric Symptom Change and Amygdala Volume After Anterior Temporal Lobectomy
}

\author{
Daniel Moadel, BA \\ Department of Neurological Surgery and Neurology, Thomas Jefferson University \\ Gaelle Eve Doucet, $\mathrm{PhD}$ \\ Department of Neurological Surgery and Neurology, Thomas Jefferson University \\ Dorian Pustina, PhD \\ Department of Neurological Surgery and Neurology, Thomas Jefferson University \\ Robert Rider, PhD \\ Department of Neurological Surgery and Neurology, Thomas Jefferson University \\ Nathan Taylor, BA \\ Department of Neurological Surgery and Neurology, Thomas Jefferson University \\ Follow this and additional works at: https://jdc.jefferson.edu/jhnj \\ Let us know, how access to this document benefits you
}

\author{
Recommended Citation \\ Moadel, BA, Daniel; Doucet, PhD, Gaelle Eve; Pustina, PhD, Dorian; Rider, PhD, Robert; Taylor, BA, Nathan; \\ Barnett, MS, Paul; Sperling, MD, Michael R.; Sharan MD, Ashwini; and Tracy, PhD, Joseph I. (2015) \\ "Emotional/Psychiatric Symptom Change and Amygdala Volume After Anterior Temporal Lobectomy," \\ JHN Journal: Vol. 10 : Iss. 1 , Article 4. \\ DOI: https://doi.org/10.29046/JHNJ.010.1.003 \\ Available at: https://jdc.jefferson.edu/jhnj/vol10/iss1/4
}

This Article is brought to you for free and open access by the Jefferson Digital Commons. The Jefferson Digital Commons is a service of Thomas Jefferson University's Center for Teaching and Learning (CTL). The Commons is a showcase for Jefferson books and journals, peer-reviewed scholarly publications, unique historical collections from the University archives, and teaching tools. The Jefferson Digital Commons allows researchers and interested readers anywhere in the world to learn about and keep up to date with Jefferson scholarship. This article has been accepted for inclusion in JHN Journal by an authorized administrator of the Jefferson Digital Commons. For more information, please contact: JeffersonDigitalCommons@jefferson.edu. 


\section{Emotional/Psychiatric Symptom Change and Amygdala Volume After Anterior Temporal Lobectomy}

\section{Authors}

Daniel Moadel, BA; Gaelle Eve Doucet, PhD; Dorian Pustina, PhD; Robert Rider, PhD; Nathan Taylor, BA;

Paul Barnett, MS; Michael R. Sperling, MD; Ashwini Sharan MD; and Joseph I. Tracy, PhD 


\section{Emotional/Psychiatric Symptom Change and Amygdala Volume After Anterior Temporal Lobectomy}

Daniel Moadel, BA, Gaelle Doucet, PhD, Dorian Pustina, PhD, Robert Rider, PhD, Nathan Taylor, BA, Paul Barnett, MS, Michael Sperling, MD, Ashwini Sharan, MD, Joseph I. Tracy, PhD

Departments of Neurological Surgery and Neurology, Thomas Jefferson University

\section{INTRODUCTION}

Patients who undergo anterior temporal lobectomy (ATL) to treat temporal lobe epilepsy (TLE) often experience worsened or de novo psychiatric symptoms. There is evidence to suggest that the pathophysiology of epilepsy and mood disorders are linked both functionally or structurally in the brain. ${ }^{1,2}$ While several studies have examined the role that changes in hippocampal volume may play in predicting post-surgical depression, the role of the amygdala in such prediction has been overlooked, despite extensive literature demonstrating its contribution to emotion processing and expression. ${ }^{3,4}$ The goal of this project was to determine if change in amygdala volume is a predictor of depression and/or anxiety in TLE patients who undergo ATL, with specific attention given to side of surgery.

\section{METHODS}

Data was collected from 32 patients who underwent ATLs (19 right, 13 left, matched samples). Pre- and post-surgery Personality Assessment Inventory (PAI) data were collected on 14 ATL patients. The following PAI subscales were utilized in this analysis: Anxiety: PAIANX; Anxiety Related Disorder: PAIARD; Depression: PAIDEP). Volumetric analysis was performed on pre- and post-surgical T1 MRIs using Freesurfer's longitudinal processing function. Left and right amygdala volumes, change scores, and amygdala asymmetry ratios were calculated taking into account whole brain volume. $55 \%$ of the patients were seizurefree after 1 year (RTLE= 8, LTLE= 9); $29 \%$ received an Engel Class score of 2 or 3 $(\mathrm{RTLE}=7, \mathrm{LTLE}=2$ )

\section{RESULTS}

The two experimental groups, right TLE and left TLE, showed no significant differences either pre- or post-ATL: age, age of seizure onset, full-scale IQ or amygdala volume or asymmetry (Table 1).

\section{Table 1: . Clinical and Demographics Characteristics of each TLE group}

\begin{tabular}{|l|c|c|c|}
\hline & RTLE & LTLE & Significant (?) \\
\hline N (female) & $18(12)$ & $13(10)$ & NS \\
\hline Age (years) & $45 \pm 12$ & $48 \pm 12$ & NS \\
\hline Years of Education & $15 \pm 2$ & $15 \pm 3$ & NS \\
\hline $\begin{array}{l}\text { Time between surgery and Second Test } \\
\text { (months) }\end{array}$ & $15.4 \pm 24.7$ & $14.7 \pm 16.2$ & NS \\
\hline Age of seizure onset (years) & $21 \pm 11$ & $25 \pm 14$ & NS \\
\hline L amygdala volume, pre-/post- surgery & $0.18 \pm 0.04 / 0.17 \pm 0.04$ & $0.17 \pm 0.07 / 0.03 \pm 0.03$ & NS/0.0 \\
\hline R amygdala volume, pre-/post- surgery & $0.19 \pm 0.06 / 0.03 \pm 0.05$ & $0.21 \pm 0.08 / 0.17 \pm 0.06$ & NS/0.0 \\
\hline Amygdala Asymmetry & $0.03 \pm 0.08 /-0.73 \pm 0.42$ & $0.11 \pm 0.06 / 0.62 \pm 0.48$ & $0.005 / 0.0$ \\
\hline Psychiatric Scores, pre-/post- surgery & \multicolumn{3}{|c|}{ NS/NS } \\
\hline PAIANX & $57 \pm 12 / 48 \pm 6$ & $53 \pm 9 / 59 \pm 13$ & NS/NS \\
\hline PAIARD & $53 \pm 12 / 49 \pm 12$ & $51 \pm 9 / 60 \pm 16$ & $0.042 / N S$ \\
\hline PAIDEP & $59 \pm 11 / 54 \pm 9$ & $51 \pm 7 / 64 \pm 18$ & \\
\hline
\end{tabular}

All measures are shown as means \pm standard deviation. Amygdala volume was calculated as a ratio with total gray matter volume. Amygdala was calculated as the difference between right and left maygdala volume rations over the combined right and left amygdala volume. Group comparisions were examined throug independent sample t-test. Abbreviations: Personality Assessment Inventory measures Anixiety (PAIANX), Anxiety Related Disorders Depression (PAIDEP). 
Table 2: Post Surgical Psychiatric Scores. Results of regression analyses for PAIDEP, PAIANX, and PAIARD scores to amygdala volume, amygdala volume change, amygdala pre-surgery, and amygdala asymmetry change measurements. Significant results are marked with an asterisk.

\begin{tabular}{|c|c|c|c|}
\hline Model & $\begin{array}{c}\text { PAIDEP } \\
\text { Adj. } R^{2}=0.64, F[7,15]=4.7, p=0.02\end{array}$ & $\begin{array}{c}\text { PAIANX } \\
\text { Adj. } R^{2}=0.56, F[7,15]=3.7, p=0.04\end{array}$ & $\begin{array}{c}\text { PAIARD } \\
\text { Adj. } R^{2}=0.6, F[7,15]=4.2, p=0.03\end{array}$ \\
\hline & Stand. b Coef., p-value & Stand. b Coef., p-value & Stand. b Coef., p-value \\
\hline ATL group & $-0.24, .0 .68$ & $1.2,0.08$ & $0.57,0.35$ \\
\hline Left AMYG vol, pre-surg. & $6.5,0.008^{*}$ & $4.5,0.06$ & $5.8,0.02 *$ \\
\hline Right AMYG vol, pre-surg. & $-5.9,0.02^{*}$ & $-4.2,0.08$ & $-5.2,0.03^{\star}$ \\
\hline Left AMYG vol change & $-0.46,0.72$ & $-0.38,0.79$ & $-1.2,0.38$ \\
\hline Right AMYG vol change & $4.4,0.005^{*}$ & $2.5,0.08$ & $4.2,0.009 *$ \\
\hline AMYG asym., pre-surg. & $4.7,0.02$ & $3.2,0.11$ & $4.1,0.04 *$ \\
\hline AMYG asym., change & $-3.9,0.04^{*}$ & $-3.5,0.08$ & $-5.3,0.01^{*}$ \\
\hline
\end{tabular}

Results of regression analyses for PAIDEP, PAIANX, and PAIARD scores to amygdala volume, amygdala volume change, amygdala pre-surgery, and amygdala asymmetry change measurements. Significant results are marked with an asterisk.

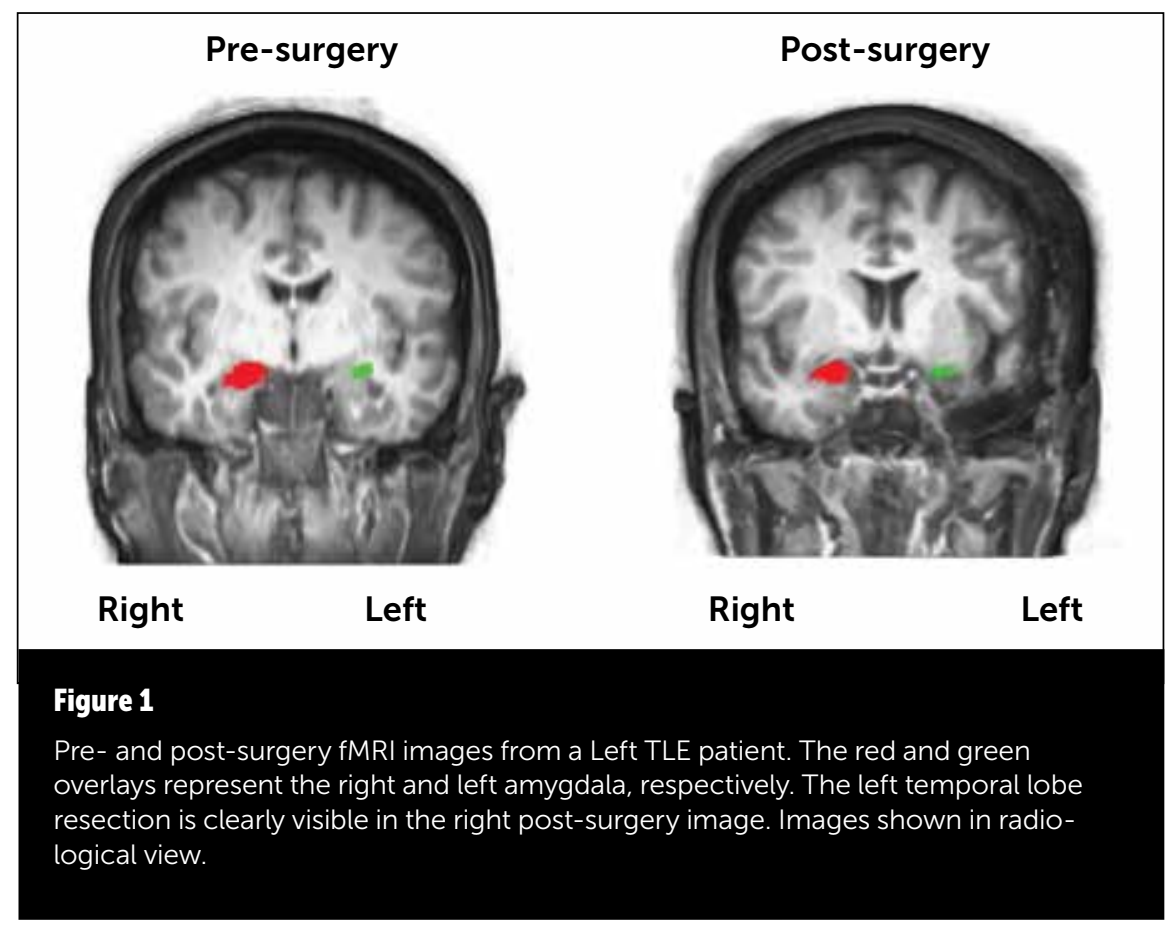

There is a change post-surgery in PAIANX $(F[1,12]=6.6, p=.02)$, PAIDEP $(F[1,12]=8.2, p=.01)$ and PAIARD $(F[1,12]=4.5, p=.05$; see Figure 2$)$ that varies for both the left and right ATL groups, such that the RATL group symptom levels went down and LATL group levels went up.
Regression analysis showed that measures of amygdala volume, amygdala volume change, and amygdala asymmetry predict post-surgery PAIANX, PAIDEP, and PAIARD, explaining approximately $36 \%$ of the variance in each of these variables, though the individual beta coefficients were significant for only PAIARD and PAIDEP (Table 2).
Examined within each ATL group, this regression model was only significant for PAIARD in the right ATL group.

The above regression model remained significant when ATL group was included as a predictor, and also after accounting for pre-surgery PAI scores and age of seizure onset.

Correlational analyses showed that change in the ratio or asymmetry of right to left amygdala volume may result in post-surgical psychiatric symptom change in right but not left ATL patients, with loss of the right sided volume associated with decreases in PAIANX ( $r=-.77)$, PAIDEP (-.86), and PAI ARD (-.95).

\section{CONCLUSIONS}

Psychiatric symptoms changed in both left and right TLE, however, the direction of the effects differed. The left group consistently showed a worsening of symptoms. This suggests left more than right ATL disrupts emotion regulation systems, potentially placing patients at higher risk for deleterious post-surgical emotional/psychiatric change.

A multivariate combined model of amygdala volume, volume change, and asymmetry does predict post-surgical anxiety (rumination, tension), depression, and anxiety related disorders (phobia, trauma stress response). Increases in right 


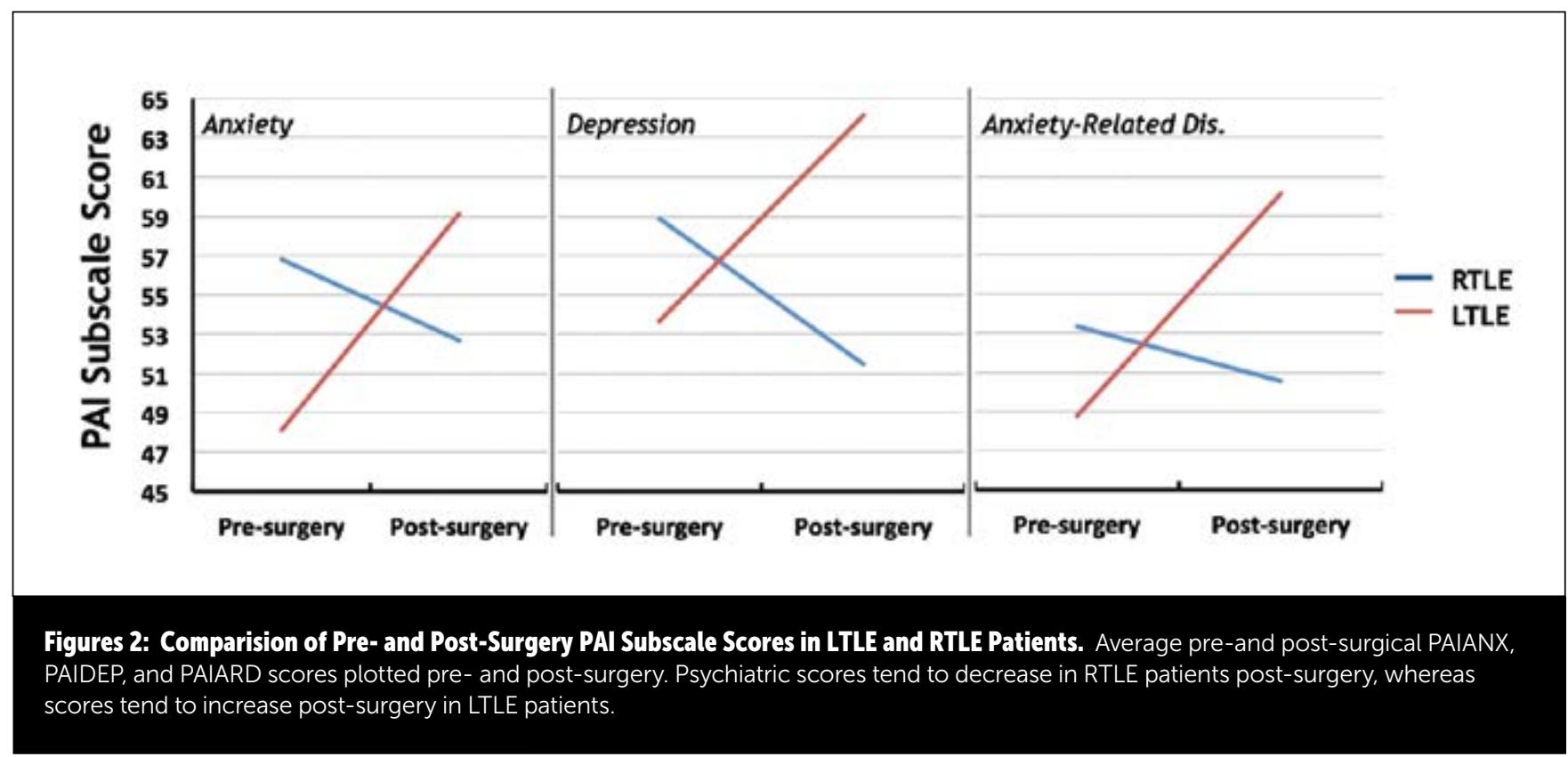

amygdala volume and decreases in left amygdala volume related to higher levels of psychiatric symptoms post-surgery, but this effect needs to be retested in larger samples as it does not distinguish the separate effects in right and left ATL. There were some indications these associations with amygdala volume may be strongest with the PAI ARD variable in the right $A T L$ group.

When viewing psychiatric symptoms alone, preliminary results suggest left ATL patients may fare worse post-surgery in terms of psychiatric symptoms. In contrast, associations with volume reveal that right $A T L$ patients may be more sensitive to the ipsilateral amygdala loss than left patients, with reduction in this pathologic zone reducing levels of depression, anxiety, and anxiety/stress related symptoms.

The data suggest the catalyst of symptom change differs in the two ATL groups, with the left group more susceptible to causes less related to brain structure and more related to diminished dominant hemisphere functions (e.g., language/ memory), and their negative impact on communication or vocational skills. In contrast, psychiatric symptom change in right ATL appeared more closely aligned with structural change (loss) in the ipsilateral amygdala, reducing pathologic emotion processing. An effect that may be related to the tendency for the right hemisphere to be dominant for emotion processing and regulation.

\section{ACKNOWLEDGMENTS}

This work was supported, in part, by the National Institute for Neurological Disorders and Stroke (NINDS) [grant number R21 NS056071-01A1] to Dr. Joseph I. Tracy

\section{REFERENCES}

1. Tracy JI, Dechant V, Sperling MR, Cho R, Glosser D. The association of mood with quality of life ratings in epilepsy. Neurology. 2007;68(14):1101-1107.

2. Tebartz van Elst L, Woermann F, Lemieux L, Trimble MR. Increased amygdala volumes in female and depressed humans. A quantitative magnetic resonance imaging study. Neurosci Lett. 2000;281(2-3):103-106.

3. Kanner AM. Hippocampal atrophy: another common pathogenic mechanism of depressive disorders and epilepsy? Epilepsy Curr. 2011;11(5):149-150.

4. LeDoux JE. Emotion circuits in the brain. Annu Rev Neurosci. 2000;23:155-184.

5. Cleary, R. A., Thompson, P. J., Fox, Z., \& Foong, J. (2012). Predictors of psychiatric and seizure outcome following temporal lobe epilepsy surgery. Epilepsia, 53(10), 1705-1712.

6. Foong, J., \& Flugel, D. (2007). Psychiatric outcome of surgery for temporal lobe epilepsy and presurgical considerations. Epilepsy Research, 75(2-3), 84-96.
7. Reuter, M., Schmansky, N.J., Rosas, H.D., Fischl, B. (2012). Within-Subject Template Estimation for Unbiased Longitudinal Image Analysis. Neuroimage 61 (4), 1402-1418.

8. Rudzinski, L. A., \& Meador, K. J. (2013). Epilepsy and neuropsychological comorbidities. CONTINUUM Lifelong Learning in Neurology, 19(3), 682-696.

9. Wilson, S. J., Bladin, P. F., \& Saling, M. M. (2004). Paradoxical results in the cure of chronic illness: The "burden of normality" as exemplified following seizure surgery. Epilepsy and Behavior, 5(1), 13-21. 